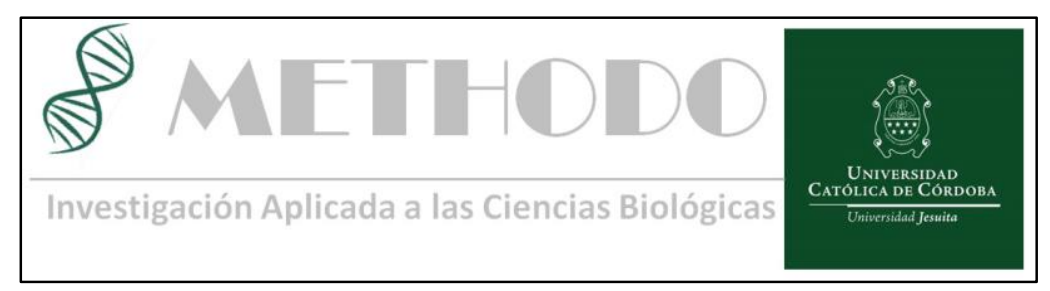

CONFERENCIA Methodo 2018;3(1): 04-05 DOI: $10.22529 / \mathrm{me} .2018 .3(1) 02$

Solicitado 14 Ago 2018| Recibido 16 Ago 2018 | Publicado 30 Mar 2018

\title{
Humanismo: Impacto en el saber
}

\section{Humanism: Impact on knowledge}

\author{
Gómez AJ, sj ${ }^{1}$.
}

Discurso del Padre Rector, Dr. Alfonso José Gómez, sj, con motivo del inicio del año académico 2018 de la Universidad Católica de Córdoba.

1. Rectorado, Universidad Católica de Córdoba Correspondencia: RP Alfonso Gómez, sj. Avenida Armada Argentina 3555. X5016DHK Córdoba, Argentina. Te. 0351-4938000 int 101 e-mail: rector@ucc.edu.ar

La dimensión humanista es una de las características distintivas del modo de enseñar de la Compañía de Jesús. Desde hace siglos, antes de estudiar filosofía y teología, los jesuitas somos introducidos en la literatura; la historia y las lenguas clásicas (latín y griego). Sensibilidad y conciencia presente en los estudios de humanidades que proponemos en la actualidad dentro de nuestra Licenciatura en Filosofía.

La visión humanista de los jesuitas en los siglos XVII y XVIII en nuestra región dieron lugar a inspiradoras síntesis culturales como aquella entre los pueblos guaraníes que abarca logros: tanto artísticos, en escultura, pintura y música; como técnicos, por ejemplo, en la arquitectura; el cultivo de la yerba mate y la fabricación de armas para la defensa; o sociales como el cabildo indígena o el sistema económico de las reducciones. 
La centralidad de la persona humana y la valoración de lo profundamente humano permitieron a la educación ignaciana dialogar con las culturas a nivel planetario y a lo largo de siglos, por ejemplo: con el barroco europeo, con los pueblos originarios de América o las milenarias culturas del Lejano Oriente, con las ideas republicanas sobre la dignidad de las personas en el siglo XIX, con propuestas de desarrollo, justicia social y de conciencia ambiental durante el siglo XX.

La dimensión humanista permite en nuestro tiempo dialogar con las narraciones y los paradigmas que buscan interpretar y conducir el enorme poder de la ciencia y la técnica.

Dinamismos tan potentes que pretenden generar una confianza en sí mismos fuera de toda crítica. Poderosos instrumentos de generación de productos, de relaciones sociales, de ofrecimiento de posibilidades impensadas hasta hace poco para el sentir, el pensar y el hacer humano.

Cultivar la lucidez humanista integral e integradora es de vital importancia. Porque nunca antes la humanidad ha generado con tanta velocidad adelantos tecnológicos. Nunca antes generó tantas encrucijadas en las que la vida humana se pueda ver enormemente favorecida o amenazada por los frutos de la ciencia.

Es necesario cultivar un humanismo, con su antropología, como el que puede derivarse de la cosmovisión cristiana para ordenar y orientar las enormes capacidades que nos dan las prótesis físicas, biológicas y del área del conocimiento que ofrece la técnica. El pensamiento lógico, argumentado, profundo, crítico y capaz de evitar reduccionismos propios de una buena filosofía es fundamental para hacer de la oportunidad un logro para la sociedad en su conjunto y no un drama con pocos beneficiados.

Es necesaria una visión humanista que tenga clara la centralidad de la persona; la pertenencia al pueblo de la humanidad y a la casa común que es la tierra. Lucidez capaz de recordar constantemente que: "no todo lo posible para la ciencia es conveniente", "ni toda novedad técnica es progreso". Es necesario un compromiso humanista que nos una en la diversidad gracias al respeto, la atención a lo complejo y la mirada de largo plazo de quien agradece la vida humana, no como un elemento más del mundo, sino como algo irreducible a medio o a cosa, algo no descartable, con una dignidad tan alta que los cristianos, por la fe, consideramos al ser humano creado a imagen de Dios y hasta capaz de familiaridad con Dios.

Parafraseando a un humanista; gran filólogo y sabio hombre de gobierno jesuita, el P. Peter Hans Kolvenbach, $\mathrm{sj}^{*}$. podremos tener delante a los mejores docentes y expositores; podremos tener asombrosos medios de aprendizaje y potentes procesos de seguimiento, y la Universidad intentará que así sea, pero el principal responsable del aprendizaje es, siempre, cada uno y lo mejor de su conciencia.

Para la fe cristiana, cada uno y el Espíritu Santo, el maestro interior que mueve lo mejor de la conciencia de cada persona, de cada grupo y de cada pueblo. Quien lleva a la plenitud humana y a la plenitud de la filiación divina simultáneamente.

Entonces, cualquiera sea nuestra creencia: ¡Que todos seamos fervorosos seguidores de nuestro Maestro interior!

Gracias por su atención

*29º superior general de la Compañía de Jesús desde 1983 hasta 2008.

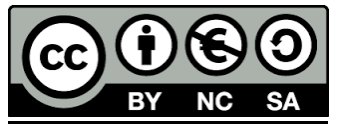

